Proceedings

\title{
The recovery of non-residential vacant plots in southern Ma- drid districts through green infrastructure implementation
}

\author{
Miguel Ángel Ajuriaguerra Escudero 1,* and Alba Ramírez Saiz 2,*
}

1* Universidad Rey Juan Carlos; miguelangel.ajuriaguerra@urjc.es

2* Universidad Politécnica de Madrid; albaramirezs@outlook.com

\begin{abstract}
The current climatic and health crisis has led, once again, to the questioning of urban planning of today's cities. This article collects the social demand from Usera and Villaverde districts in Madrid and shows the necessities of their compact and dense urban fabric derived from the obsolete configuration of real estate parks from the 1960s-70s Spanish Developmentalism. Quality public spaces and safe mobility can be potentially covered through the implementation of green infrastructures across the inter-block spaces, improving usability, mobility, and interior-exterior accessibility, while taking advantage of the large green perimeter available in both districts.
\end{abstract}

Keywords: Urban regeneration, Inter-block spaces, Environmental recovery strategy, Accessibility, Green Infrastructure.

\section{Introduction}

The current health crisis and, more specifically, the lockdown processes have brought back the questioning of how our cities have evolved in recent decades. Although this is not the first SARS outburst, its worldwide impact has led to stronger actions towards the renovation of current urban structures [1]. This is the case of Usera and Villaverde districts, both located in the southern arc of Madrid (Figure 1) and highly affected by the urban deficit at the peak point of the pandemic [2].
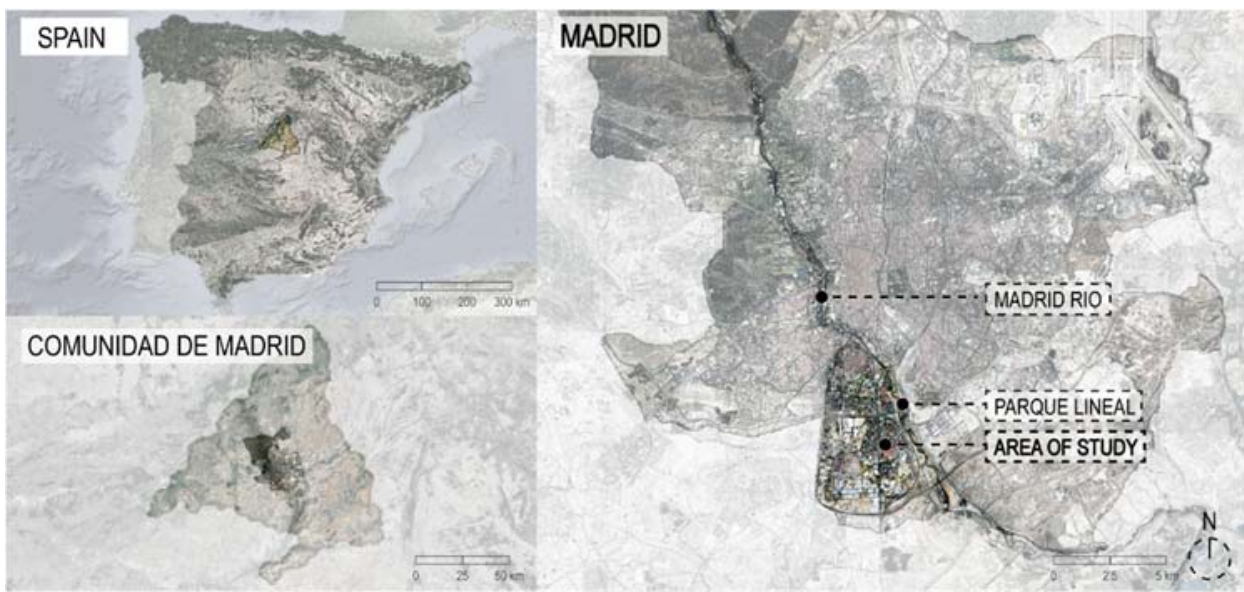

Figure 1. Location of the area of study. Author's editing, 2021.

There is also a need for public, quality services, where neighbors can enjoy a decent urban environment, as well as use it to cover all specific requirements from it in the context of a health crisis. This should be the case of social distance, proximity services and air quality. Compact patchwork areas, such as Usera and Villaverde, exhibit an unproportionate ratio of car land use over pedestrian-friendly spaces. This widths below 1 meter, 
most of the sidewalk extension tends to present deficiencies, inaccessibility and disconti- 1 nuities that constrain the walkability of city users.

Urban actions, involving both public and private agents [3] can trigger integral solutions that would facilitate a positive approach towards city interventions in the area, mostly involving Parque Lineal and Manzanares River resources. Thus, this article seeks to unearth problematic aspects in terms of green infrastructures in Usera and Villaverde districts. An in-depth study would locate vacant spaces in which walkable, green, public infrastructures are needed and possible to develop, so as to relieve urban patchwork stress by creating quality and secure green inter-linked spots [4].

\section{Area of study}

In the '50s, Usera and Villaverde District absorbed significant migratory processes from rural regions, who located in this area in slums and self-constructed houses [5]. This new workforce supported the rise in industrial production that was happening in this part of Madrid [6], consolidating new factory activities aligned to the watercourse [7]-[8].

This period, also known as Spanish Developmentalism, fostered the relocation of industrial activity from the traditional nodes like Arganzuela, to what today is known as Usera and Villaverde [9]. Their dismantling in the '90s freed spaces, immediately occupied by new residential areas which today accommodate the studied districts [10].

As a matter of fact, in this same period, Manzanares River restoration strategies tried to position Madrid as one of the top international forces [11]. The river's shore not only connects multiple districts along with Usera and Villaverde, but also provides new services and infrastructures for the neighborhoods to [12]-[13]. Several plans were conceived aiming to improve the quality of the running water, likewise its surroundings while deploying solutions to new economic, social and urban demands.

However, most of the undertaken actions only focused on the medium basin, such as the renowned "Madrid Rio" project, which was linked to the city center. These did not affect Villaverde and Usera in the south basin, but incremented the division between the city center and the south of Madrid. As a result, a project of its own called "Parque Lineal" was created, separately from both Madrid Río and the inner neighborhoods (Figure 1, 2).

Aging, Aporophobia or rejection of the poor, Racism or rejection of other cultures or races, Urban security and well-being, Urban health, Services accessibility and Usability, Universal accessibility, Lack of green infrastructures and recreational spaces, and Building inequalities are only some of the issues that the area presents.

The exclusion and degradation suffered in Usera and Villaverde have reflected on their urban physiognomy, creating inefficient urban processes and consolidating a lowincome tendency inherited from the Spanish Developmentalism period. Currently, it is at high risk of poverty, as the results of the last Indicators Panel of Madrid reflect [14]. Dismantling and obsolescence have reigned over restoration and conservation, which led to an extensive appearance of vacant land (more than $3.000 .000 \mathrm{~m}^{2}$ ), with little or no use [15].

\section{Methodology}

The main goal of this article is to study whether those vacant plots have the power to free some urban space and connect the inner neighborhoods to the green infrastructure. The hypothesis is that these spaces can be transformed into usable infrastructures which can create a green net of urban spaces, connecting Madrid Rio and the inner neighborhoods to the Parque Lineal. It will be tested in the form of personal interviews placed in singular locations along the Manzanares River line in Usera and Villaverde Districts (Parque Lineal), to study the current relationship of the neighbors with the Manzanares River. A total of 21 points were selected (Figure 2).

Parallelly, a total of 126 interviews were carried out in the form of a structured survey with 6 sections: 1. Age; 2. Employment situation; 3. Neighborhood and district of 
residence; 4 . The existence or not of green infrastructure in their area (1'-2' walk); and 5.1 Parque Lineal's score for usability, accessibility, and well-being.

The extracted results merged in a graphical proposal of an integrated green infrastructure that could connect the inner neighborhoods to Parque Lineal, as well as to the nearest margins of Usera to Madrid Río.

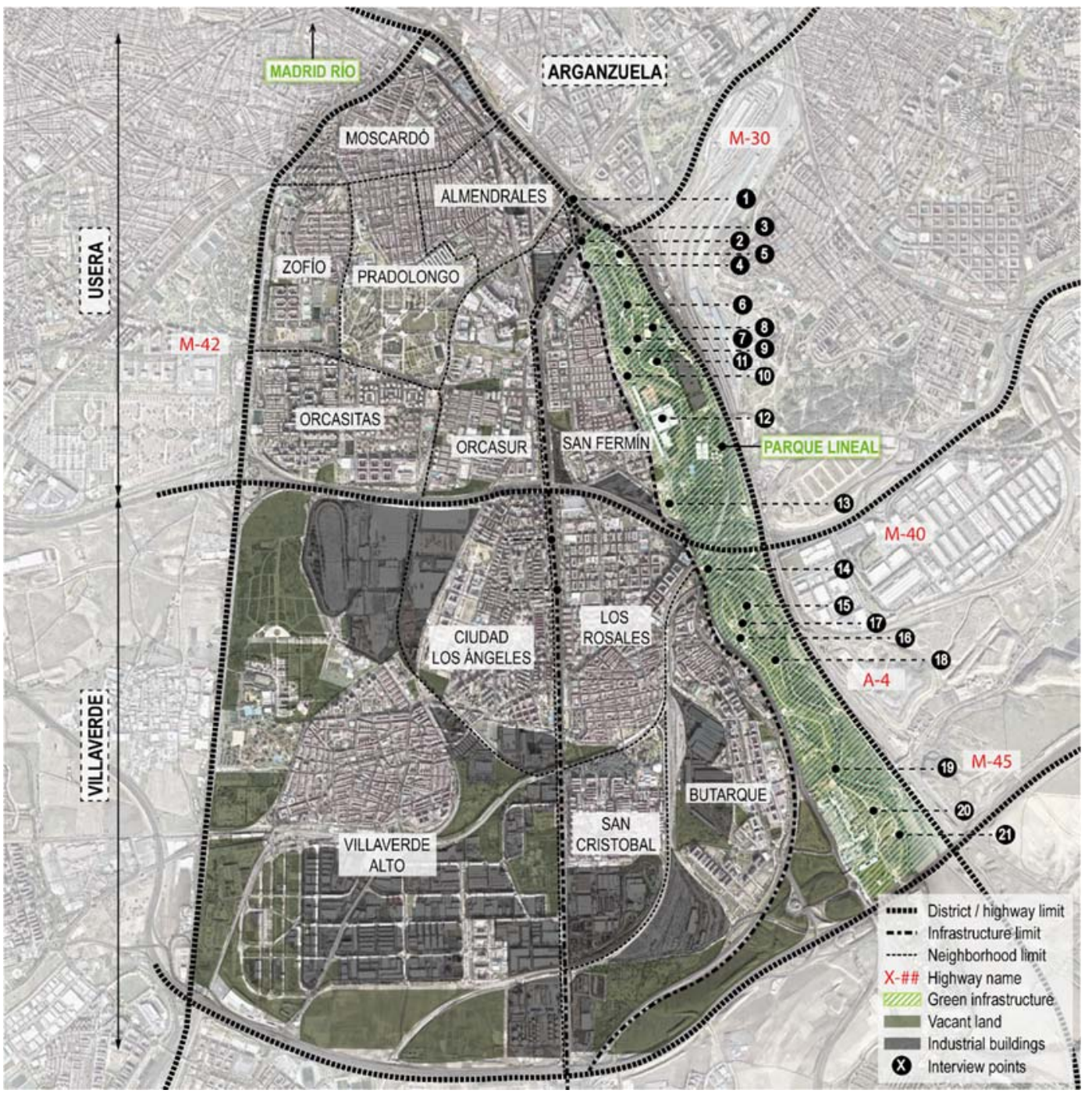

Figure 2. Location details of the area of study. Author's editing, 2021.

\section{Results}

The most relevant results for each section of the interview are as follows:

1. There are different sections in the Parque Lineal, each of them engaging different age groups, with an average attending age of 43,5 .

2. $37 \%$ of users were employed, $22 \%$ were unemployed, $21 \%$ were retired, and $20 \%$ were students.

3. The neighborhoods with higher rates of attendance were San Fermín, Ciudad de los Ángeles and Los Rosales, being only the first and the third right next to the park. Attendees from every neighborhood were found in the park.

4. Around $30 \%$ of the interviewed people claimed to have green spaces in their nearest area, although they are not always accessible, safe, or usable.

5. The Parque Lineal is, generally speaking, well-considered, with $60 \%$ of positive ratings for well-being, $49 \%$ for accessibility, and 55\% for usability. 


\section{Conclusions}

It is clear that vacant spaces can be a great opportunity to solve mobility and quality public spaces in these districts. Lack of green infrastructures makes Parque Lineal the millstone for most of the residents since their closest surrounding is unable to provide them. By implementing an accessible, safe, and usable green network, it would be possible for citizens to walk around their area, enjoy a better quality of life, and reach Parque Lineal more easily. Thus, residual and obsolete spaces, which currently constitute areas of vandalism and low walkability, would be transformed into functional spots and itineraries for people to use.

Funding: This research received no external funding.

Acknowledgments: This article was supported by Madrid Borde Sur Research Group, which both authors are part of.

Conflicts of Interest: The authors declare no conflict of interest.

1

2

3

4

5

6

7

8

a gran escala durante el proceso de construcción del área metropolitana de Madrid en la cohesión social de la ciudad. Rev. INVI 26, 73-102 (2011).

8. Valle, R. M. G. del. Crisis económica y difusión industrial en la aglomeración de Madrid. An. Geogr. Univ. Complut. 3, 175-175 (1983).

9. Lozano, M. A. Atlas de la Comunidad de Madrid en el umbral del siglo XXI: imagen socioeconómica de una región receptora de inmigrantes. (Editorial Complutense, 2002).

10. Rodríguez, E. de S. Una lectura de las políticas de suelo y los modelos urbanísticos madrileños desde mediados de los años 1990: de la liberalización a la resaca inmobiliaria. Geopolíticas Rev. Estud. Sobre Espac. Poder 3, 83-116 (2012).

11. Fernández Güell, J. M. Madrid: A tale of an ambitious city that failed to fulfil its global vision. Plan. Rev. 50.1, 6-15 (2014).

12. de Coca Leicher, J. \& Fernández Alonso, F. LA RENOVACION DEL MANZANARES: TRANSFORMACIONES Y RECICLAJES URBANOS / Renewal of Manzanares: urban transformations and recycling. Proy. Prog. Arquit. 88-105 (2011) doi:10.12795/ppa.2011.i4.06.

13. Fernández, F. \& Villanueva, A. Plan de Renovación Urbana del entorno del Río Manzanares en Madrid. Territ. Urban. Sostenibilidad Paisaje Diseño Urbano (2013).

14. Resumen de resultados del Panel de Indicadores de Distritos y Barrios de Madrid. 270 (2017).

15. Brandis, D. \& Del Río, I. Diez años creando periferia en Madrid. (1999).

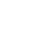

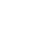

8
1

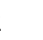

